\title{
Violência institucional: vivências no cotidiano da equipe de enfermagem
}

\author{
Institutional violence: routine experiences of the nursing team \\ Violencia institucional: vivencias en el cotidiano del equipo de enfermería
}

\begin{abstract}
Ana Maria Ribeiro dos Santos'. Juliana de Cássia Nunes Soares', Luciana Ferreira Nogueira', Nayra Assunção Araújo', Gerardo Vasconcelos Mesquita', Clara Francisca dos Santos Leal'
\end{abstract}

'Universidade Federal do Piauí. Departamento de Enfermagem. Teresina, PI

Submissão: $21 / 10 / 2009$

Aprovação: 26/09/2010

\section{RESUMO}

Estudo Qualitativo que objetivou descrever a vivência dos profissionais da equipe de enfermagem expostos à violência institucional, discutir como essas vivências influem no cotidiano e na organização do serviço e conhecer os eventos causadores dessas atitudes violentas. Os sujeitos foram onze profissionais da equipe de enfermagem. Os dados foram produzidos por meio de entrevista, analisados utilizando técnica de análise temática, organizados nas categorias: vivências de violência na equipe de enfermagem, influência da violência no cotidiano de trabalho e na organização do serviço e fatores causadores de atitudes violentas contra a eQuipe de enfermagem. Os resultados demonstram Que os profissionais encontram-se susceptíveis a atitudes violentas no ambiente de trabalho por permanecerem mais tempo e em maior interação com pacientes e acompanhantes.

Descritores: Violência; Equipe de enfermagem; Trabalho.

\section{ABSTRACT}

The purpose of this Qualitative study was to describe the experience of a professional nursing team exposed to institutional violence, to discuss how these experiences influence their routine lives and their service organization as well as learn about the events which provoke these violent attitudes. The subjects of this study were eleven professionals of the nursing team. Data was collected through interviews and analyzed by using thematic analysis, organized in categories: violent situations involving the nursing staff, the influence of violence in the workplace and service organization and contributing causes of violent attitudes against the nursing team. The results show that professionals are more prone to violent behavior in the workplace due to longer permanence and greater interaction with patients and caregivers.

Key words: Violence; Nursing team; Work.

\section{RESUMEN}

Estudio cualitativo que objetivó describir la vivencia de los profesionales del equipo de enfermería expuestos a la violencia institucional, discutir como esas vivencias influyen en el cotidiano y en la organización del servicio y conocer los eventos causadores de esas actitudes violentas. Los sujetos fueron once profesionales del equipo de enfermería. Los datos fueron producidos por medio de encuesta, analizados utilizando técnica de análisis temática, organizados en las categorías: vivencia de violencia en el equipo de enfermería, influencia de la violencia en el cotidiano de trabajo y en la organización del servicio y factores causadores de actitudes violentas contra el equipo de enfermería. Los resultados demonstran Que los profesionales se encuentran susceptibles a actitudes violentas en el ambiente de trabajo por permanecieren más tiempo y en mayor interacción con pacientes y acompañantes.

Descriptores: Violencia; Equipo de enfermería; Trabajo. 


\section{INTRODUÇÃO}

A violência é considerada um problema social e de saúde pública, com origens e consequências variáveis, ocasionadas por indivíduos, grupos, classes ou nações Que geram danos a uma ou várias pessoas em diferentes graus, seja em sua integridade física, moral, emocional ou espiritual ${ }^{(1)}$.

Anualmente, mais de um milhão de pessoas morrem e muitas sofrem ferimentos resultantes de atos violentos. Nesse sentido, chama atenção o fato de a violência configurar-se como uma das principais causas de morte nos indivíduos na faixa etária de 15 a 44 anos $^{(2)}$.

No Brasil, a Política Nacional de Redução da Morbimortalidade por Acidentes e Violência evidencia Que o impacto econômico desse fenômeno pode ser medido diretamente por meio dos gastos hospitalares com internação, incluindo unidades de terapia intensiva e de permanência geral. Por essas razões citadas, essa política estabeleceu diretrizes e responsabilidades institucionais, contemplando e valorizando medidas ligadas à promoção da saúde e a prevenção desses eventos ${ }^{(3)}$.

A violência é classificada de diversas formas, em diferentes tipos, de acordo com a visão de cada pesquisador. Dentre as várias classificações a ela atribuídas têm-se a violência institucional, aQuela Que se realiza dentro das instituições, sobretudo por meio de suas regras, normas de funcionamento e relações burocráticas e políticas, reproduzindo as estruturas sociais injustas ${ }^{(4)}$.

A violência institucional é abordada como um fato presente no cotidiano do trabalho hospitalar, e definida sob dois aspectos: por omissão e por comissão. A primeira engloba a negligência e o descaso em relação aos usuários do sistema de saúde não atendendo, assim, a suas necessidades básicas. A segunda relacionase a procedimentos desnecessários e/ou indesejáveis, voltando-se ao aspecto técnico da assistência ${ }^{(5)}$.

A violência no local de trabalho engloba insultos, ameaças, agressão física ou psicológica originadas de pessoas exteriores à organização, incluindo clientes, contra alguém Que está trabalhando constituindo um risco para a saúde, segurança e bem-estar dos trabalhadores ${ }^{(6)}$.

Esse tipo de violência é uma das principais causas de mortes e ferimentos no mundo. Nos Estados Unidos, segundo estatísticas oficiais, o assassinato representa a primeira causa de morte no local de trabalho para as mulheres e a segunda principal entre os homens. Na União Europeia, cerca de 3 milhões de trabalhadores ( $2 \%$ do total) já foi submetido a alguma forma de violência física no trabalho, e na Suécia, calcula-se que tal comportamento seja o fator responsável por $10 \%$ a $15 \%$ dos suicídios. Pesquisa realizada no Reino Unido revelou Que 53\% dos funcionários já sofreram intimidação no trabalho e $78 \%$ testemunharam tal comportamento. $\mathrm{Na}$ África do Sul, estudo recente mostrou Que 78\% dos entrevistados tinham experimentado bullying no local de trabalho ${ }^{(7)}$.

No Brasil, os profissionais de enfermagem vivenciam constantemente a precarização do trabalho, por terem, entre outros fatores, uma trajetória marcada pela jornada de trabalho aumentada devido ao acúmulo de empregos, à Quantidade insuficiente de pessoal, além da convivência com situações de morte Que têm influência no caráter psicológico. Com isso, esse Quadro pode contribuir para a realização de uma assistência ineficaz, podendo resultar em atitudes violentas dos pacientes e/ou acompanhantes contra a equipe ${ }^{(8)}$.

Nesse contexto, definiu-se como objeto de estudo a violência institucional vivenciada no cotidiano da equipe de enfermagem. $\mathrm{E}$, como objetivos, descrever a vivência dos profissionais da equipe de enfermagem expostos à violência institucional em um hospital de ensino, discutir como essas vivências influem no cotidiano desses profissionais e na organização do serviço de saúde, bem como conhecer os possíveis eventos causadores dessas atitudes violentas.

$\mathrm{Na}$ atualidade, o tema tem ganhado espaço nas pesquisas na área da saúde, como também se pode perceber, através de situações presenciadas e relatos de casos, a existência de violência de pacientes e/ou acompanhantes em relação aos profissionais da equipe de enfermagem dentro do seu ambiente de trabalho. Esse fato vem resultando em grande desgaste psicológico dos profissionais, afetando diretamente o desenvolvimento de um cuidado adequado.

\section{MÉTODOS}

Pesquisa de abordagem Qualitativa realizada em um hospital público de ensino de grande porte, localizado no município de Teresina, PI, Que atende, em sua maioria, pacientes oriundos do próprio Estado, como também de estados vizinhos como Maranhão e Ceará.

Os sujeitos participantes deste estudo foram I I profissionais da equipe de enfermagem, Que desenvolvem atividades nas clínicas Ortopédica, Neurológica, Urológica e Especializada, cujos pacientes apresentam patologias Que exigem tempo de internação mais prolongado. É importante ressaltar que essa última clínica recebe pacientes de diferentes especialidades, sendo que grande parte deles são transferidos do hospital de urgência do município, vitimados por acidentes e violências, e apresentam problemas ortopédicos que requerem internação demorada.

Os critérios de escolha dos sujeitos foram a disponibilidade e o consentimento em participar do estudo. Foi considerado critério de exclusão a resposta negativa Quando estes foram interrogados se já haviam sofrido algum tipo de violência no local de trabalho.

Tomando por base os critérios da Resolução no 196/96 do Conselho Nacional de Saúde os participantes foram informados sobre os objetivos do estudo e em seguida foi solicitada a assinatura do termo de consentimento livre e esclarecido, do Qual todos receberam uma cópia, em Que há clareza Quanto aos aspectos da pesquisa em relação ao respeito à dignidade humana. Também lhes foi garantido o anonimato das informações através da identificação dos depoentes, conforme a sua categoria profissional, por letras maiúsculas do alfabeto latino $\mathrm{E}, \mathrm{TE}, \mathrm{AE}$, correspondendo respectivamente a enfermeiro, técnico e auxiliar de enfermagem, seguidas de algarismo arábico correspondente ao número do entrevistado em sua categoria profissional.

Optou-se pela entrevista como técnica de produção de dados, utilizando um roteiro semi-estruturado. Para registrar a fala dos depoentes, utilizou-se um gravador e em seguida as informações foram transcritas na íntegra. Adotou-se como critério para encerramento das entrevistas a saturação das falas. A discussão dos dados produzidos foi realizada por meio da análise temática, objetivando descobrir os núcleos de sentido da comunicação, a fim de revelar os valores presentes nos discursos. Na pesquisa se utilizou as três etapas recomendadas no referido método de análise, 
a saber: pré-análise, exploração do material, tratamento dos resultados e interpretação ${ }^{(9)}$.

O estudo foi encaminhado inicialmente à Comissão de Ética em Pesquisa do hospital público de ensino onde foi realizada a produção dos dados. Em seguida, submeteu-se à análise do Comitê de Ética e Pesquisa da NOVAFAPI com protocolo de $\mathrm{n}^{\circ}$ 0054.0.043.00009 , ressaltando Que somente após a autorização de ambos, a pesquisa foi iniciada.

\section{RESULTADOS E DISCUSSÃO}

A violência institucional contra profissionais de saúde é um fato preocupante e cada vez mais presente nos cenários da prática em saúde. Nesse sentido, as categorias de análise construídas a partir das falas das depoentes permitem conhecer suas vivências e como elas influenciam em seu cotidiano de trabalho, assim como ao Que atribuem à ocorrência desse fenômeno.

Estes dados produzidos foram obtidos a partir dos depoimentos de dois enfermeiros, seis técnicos e três auxiliares de enfermagem. Através de perguntas fechadas identificou-se a categoria profissional dos entrevistados e observou-se Que o tempo de serviço na instituição varia de um a mais de dez anos, com predomínio dos profissionais Que prestam serviço há mais de dez anos.

\section{Vivências de violência na equipe de enfermagem prioritariamente expressa por violência verbal}

Acredita-se que dentre os profissionais de saúde, aqueles pertencentes à equipe de enfermagem encontram-se mais susceptíveis a vivenciar episódios de violência no seu ambiente de trabalho, devido à maior aproximação com pacientes e acompanhantes.

Os atos de violência cometidos contra essa equipe acontecem de formas diferentes, podendo ser de ordem física ou verbal como pode ser observado nas falas a seguir:

O paciente chegou... me abordou aqui na porta do posto me agredindo com palavras, dizendo que eu não sabia de nada, Que eu Queria mandar no hospital, Que eu Queria mandar na clínica, Que ele ia me processar, Que ele tinha os direitos dele. E apontando o dedo pra mim e tudo... muito agressivo. (EI)

[... I a esposa do paciente estava deitada junto com ele debaixo dos lençóis. Falei que não podia deitar com o paciente [...] Aí ele me ameaçou, disse que ia me levar pra Ouvidoria. Eu disse Que ela podia ir Que eu estava no meu direito. (TE2)

[...] Eu já sofri várias agressões, física não, só porque a gente corre, porque tem perna pra correr, mas uma vez (...) o acompanhante, disse: vocês são isso, são aquilo! Usou vários termos bem baixos. Vocês ficam caminhando pra lá e pra cá, não dão assistência. E no momento se eu não tivesse me afastado, ele tinha jogado o suporte de soro em cima de mim. E uma amiga minha também, com um dos suportes ele ia agredi-la. (E2)

A partir dos depoimentos acima pode-se perceber Que a maioria das atitudes violentas vivenciadas pelos profissionais de enfermagem são de caráter verbal, através de insultos, ameaças e difamações.
Contudo, alguns casos de violência física também foram relatados.

[...] eu sai correndo e ela puxando minha bata, até rasgou minha bata nesse tempo, sai correndo e ela atrás, aí eu fui atrás do médico. (TE3)

As agressões sofridas pelos trabalhadores de serviços de saúde podem ser físicas ou verbais. Dentre as agressões físicas, aQuelas mais presentes são: arranhar, beliscar, dar pontapés, esmurrar, dar tapas, empurrar, apertar contra a parede, morder e agredir com o uso de objetos ou armas. Já as agressões verbais ocorrem na forma de humilhações, insultos, ofensas, indicando falta de respeito com a dignidade do indivíduo ${ }^{(10)}$.

Devido à complexidade do relacionamento humano e às características próprias do homem, as relações entre as pessoas Que convivem no ambiente de internação hospitalar acontecem de forma instável, ainda Que entre os mesmos sujeitos. Existem diversas situações Que demarcam experiências de relacionamento, sendo estas positivas ou negativas ${ }^{(11)}$.

Por outro lado, mensurar a extensão da violência no ambiente de trabalho é algo complexo, uma vez Que a literatura traz conceitos diversos de violência, assim como também varia a definição do fenômeno da violência por parte das vítimas ${ }^{(10)}$.

Dessa forma, observa-se a necessidade de adequação dos serviços, criando estratégias Que possibilitem informar aos usuários sobre as rotinas adotadas nos serviços de saúde a fim de facilitar a compreensão deles sobre os procedimentos Que devem adotar enQuanto permanecerem na instituição de saúde.

\section{A influência da violência no cotidiano de trabalho e na organização do serviço de saúde}

A maioria dos entrevistados afirmou Que as vivências de violência influenciaram no seu cotidiano de trabalho, relatando terem se sentido estressados, irritados, com baixa auto-estima e desestimulados para trabalhar. Isso pode ser constatado nos depoimentos abaixo:

Não é bom pra gente não, porQue se fica com os nervos à flor da pele. É muito ruim, a gente fica tão sem gosto. Fico assim sem vontade de trabalhar, fico desestimulada. (AE I)

A gente fica estressada no momento, pode elevar até a pressão. A gente fica irritada, chocada, afeta até o psicológico. (TE2)

Eu me senti péssima, senti assim, três pontadas na minha cabeça. (...) Quando eu ouço essas coisas, fico com vontade de não fazer mais nada. (TE4)

Ameaças, xingamentos, intimidação, ofensas, humilhação, dentre outras, são expressões usuais do agressor para com os profissionais de enfermagem, além das agressões físicas. E, em geral, os profissionais Que são afetados por essa violência no trabalho têm, como conseQuência, sintomas emocionais, tais como: frustração, estresse, tristeza, raiva, desânimo, baixa auto-estima. Com isso, além do risco de agravo à saúde do próprio trabalhador, há um comprometimento no processo do cuidar devido a um possível atendimento deficiente tanto para o usuário como para o 
acompanhante.

As atitudes violentas têm efeitos inquietantes e englobam uma variedade de conseQuências preocupantes, Que incluem desde a lesão física a problemas emocionais como depressão, medo, estresse, perda da auto-estima, entre outros, comprometendo a Qualidade do serviço e cuidados prestados ${ }^{(12)}$.

Assim, a humanização dos serviços de saúde envolve a con@uista pelos trabalhadores de adequadas e saudáveis condições de trabalho, o Que implica autonomia e participação no controle dos processos de trabalho em saúde, criação de vínculos e responsabilidades $^{(13)}$.

Contudo, um depoente considerou essas vivências de forma positiva, pois propiciaram reflexões Que contribuíram para seu crescimento profissional, buscando tornar a assistência ao paciente mais humanizada. Isso pode ser evidenciado na fala a seguir:

Influenciou assim, influenciou porQue a gente cresce! Toda vez Que alguém me agrediu ou dizia essas coisas comigo ou com as minhas colegas, a gente pensa Que não aprende, mas a gente tenta melhorar (...) E eu acho Que pra mim, eu sempre melhorei. Eu fico mais humana, muito mais. Sempre me colocando que eu poderia ta ali, ou uma família minha, sempre me coloquei assim. (E2)

A partir do momento Que o profissional da saúde vivencia a experiência de violência, como ser humano, ele pode também refletir e buscar compartilhar a preocupação e sofrimento do outro, passando a considerar suas necessidades, angústias e vontades para melhor confortar o familiar ou o próprio usuário.

A humanização dos cuidados está relacionada à individualidade do ser humano e à construção de um espaço concreto nas instituições de saúde Que valorize o lado humano daqueles Que recorrem a esses serviços. Dessa forma, para Que o cuidar aconteça de maneira humanizada, os trabalhadores da saúde, em especial o enfermeiro Que presta frequentes cuidados e possui maior contato direto com o paciente, deve ser capaz de entender a si mesmo e ao outro, estendendo esse conhecimento a ações concretas e conscientizando-se dos valores e princípios Que norteiam sua ação. Para Que possa ser iniciada a busca pela humanização é necessário Que os profissionais de saúde vejam o usuário não apenas como alguém Que possui necessidades biológicas, mas como um ser biopsicossocial e espiritual que deve ter sua dignidade preservada e seus direitos respeitados ${ }^{(14)}$.

Portanto, o acolhimento é uma necessidade de saúde e a sua prática deve ser centrada no trabalho vivo cotidianamente construído, de modo individual e coletivo, produzido no encontro do trabalhador com o usuário, o verdadeiro centro do mundo das necessidades ${ }^{(15)}$.

Entretanto, outros participantes da equipe relataram que suas atividades não são influenciadas pelas atitudes violentas por estarem habituados a conviver com esse tipo de situação, o Que pode ser comprovado com as seguintes declarações:

Aí eu levo na esportiva, não me estresso... (AE2)

Não. A gente já está acostumada. Era sempre assim. Eu não fico estressada de jeito nenhum. (TEI)
A violência vivenciada pelos profissionais de saúde vem causando uma conseQuente naturalização do fenômeno, uma aceitação, como se fosse algo normal, Que não comove e não choca mais, principalmente, acredita-se devido ao fato de estar próxima e presente cotidianamente na rotina de trabalho.

Pôde-se perceber a partir das opiniões dos entrevistados Que os atos violentos podem também influenciar de forma positiva na organização do serviço de saúde. Como se observa através dos seguintes depoimentos:

Eu acho que com isso as políticas públicas mudaram, os diretores, gerentes, o próprio secretário de saúde começou a trabalhar essa mudança. Não só no hospital geral, esse grande, como nos hospitais de bairro de urgência, eles também tão mudando, mudando de estrutura, de atender melhor, vários serviços até instalaram ouvidoria. Pra Que é isso? Pra melhorar, pra conhecer os anseios da população. As mudanças têm Que ser feitas. (E2)

Na organização da clínica, eu pedi Que os funcionários tomassem mais cuidado na hora da admissão começando logo a alertar, orientar... Hoje já é feito, no decorrer dessa nova regra do diretor elas já fazem essa orientação. (E I)

Hoje eles dão uma urna, botam uma urna bem aí para acompanhantes fazerem as Queixas deles, sugestão, colocar o Que eles acham do hospital, o Que acham do tratamento, de tudo, umas perguntas de rotina e muitas vezes têm resposta na urna. (AEI)

A ocorrência de atitudes violentas dentro do ambiente de trabalho pode servir como um alerta para Que mudanças importantes ocorram na instituição, desde a adoção de novas práticas na rotina de trabalho até a implantação de ouvidorias e urnas onde é possível ter um elo entre o usuário e/ou acompanhante com o hospital, gerando, com isso, melhorias na Qualidade do serviço e uma consequente satisfação das pessoas.

Atualmente, com os princípios Que regem o atendimento à saúde, baseados na integralidade da assistência, equidade, participação social do usuário, universalidade, dentre outros, a ideia de humanização em saúde assume um papel de extrema importância, Que reQuer uma revisão das práticas cotidianas, ressaltando a criação de ambientes de trabalho menos alienantes e valorizando o trabalhador e o usuário ${ }^{(16)}$.

Assim, como a enfermagem considera o cuidado o foco central de sua prática, é necessário assumir o compromisso de lutar constantemente pela criação de vínculos e responsabilidades. Porém, isso implica uma avaliação permanente do seu fazer, reconhecimento das deficiências de infraestrutura dos serviços e da situação de vida dos usuários, para com isso tornar favorável melhoras na Qualidade da atenção prestada e na auto-realização de toda a equipe com o trabalho.

Fatores causadores das atitudes violentas contra a equipe de enfermagem

Os profissionais da equipe de enfermagem atribuem a ocorrência de atitudes violentas a diversos fatores, como pode ser observado 
nos depoimentos citados a seguir:

Ele pensa que o paciente vai morrer, entendeu?! Aí ele quer que seja atendido logo, pra não ter nada com o paciente, o paciente sobreviver. (TEI)

[... ela me pegou, assim, puxando minha bata, falou: "ei, a senhora vai matar minha mãe, a senhora vai matar minha mãe, eu lhe disse que ela é diabética, a senhora vai fazer esse soro glicosado. (TE3)

Ao presenciarem a aflição de seus familiares que se encontram enfermos surgem sentimentos de preocupação e angústia por parte dos acompanhantes, Que anseiam um tratamento imediato para evitar o sofrimento do paciente. Quando isso não ocorre de forma eficaz, engendram-se momentos de desespero e revolta, o Que pode resultar em atitudes violentas. Assim, constata-se que a comunicação é realmente um instrumento básico na prática social da enfermagem.

Ao se deparar com a hospitalização de um familiar, o acompanhante encontra-se em um ambiente estranho, com horários estabelecidos, pessoas que informam, manipulam e determinam o Que pode ou não fazer. Diante disso, o familiar nem sempre respeita a disciplina imposta, resultando em atritos principalmente com a equipe de enfermagem, Que são os profissionais Que permanecem grande parte do tempo no hospital e aos Quais o familiar tem mais acesso $^{(11)}$.

Em geral, as situações mais propícias para a ocorrência de violência contra os profissionais são: Quando o paciente está agitado, recebe más notícias, ou Quando é solicitado a fazer algo Que não deseja. Tudo isso associado a outros fatores, como a frustração com o serviço devido à espera pelo atendimento médico e estresse dos pacientes por estarem sentindo muita dor ou por se encontrar com o estado emocional abalado. Os familiares e amigos também surgem como fontes de violência devido ao estado de ansiedade e angústia perante o sofrimento do paciente $e^{(10)}$.

Os depoentes atribuíram também a causa de atitudes violentas à dificuldade de acesso ao serviço de saúde e ao estresse do dia a dia. Os relatos a seguir demonstram esse aspecto:

Eles já trazem essa carga, já trazem consigo (...) a grande maioria não tem condição financeira, aí marcam uma consulta para ser atendido não sei Quanto tempo depois, uma vida para fazer um exame, outra vida para dá o resultado, Quando ele chega aqui, Quando ele consegue uma vaga, já está estourado. (TE5)

É porque eles já chegam com os nervos à flor da pele pelo problema que estão passando com seus familiares, já chegam estressados, aí não tem jeito de se dirigir às pessoas. (TE3)

As pessoas já vêm de casa estressadas. Aí acham Que jogando o estresse deles em cima da gente vai melhorar a condição, não vai. Faz é piorar, porque a gente fica até nervosa, não tem nem condição de fazer o trabalho. (AE3)

O usuário do serviço de saúde precisa enfrentar várias etapas até Que consiga receber o tratamento de Que necessita, devido às dificuldades de acesso e ao atendimento deficiente, o que ocorre dentro de um processo demorado. Isso aliado ao estresse do cotidiano ocasionado pela sobrecarga de problemas enfrentados diariamente, cria uma situação propícia à ocorrência de agressões contra a equipe de enfermagem.

A dificuldade de acessibilidade e o acolhimento deficitário do usuário na atenção primária resultam em uma má Qualidade de atendimento em saúde. Assim, a organização dos serviços de saúde nem sempre tem a finalização do atendimento, o Que acarreta desconforto e até mesmo agressões aos profissionais ${ }^{(17)}$.

Observa-se Que apesar de a universalidade implicar, entre outros aspectos, acesso aos serviços de saúde e às informações necessárias, assim como a manutenção de um equilíbrio físico e mental saudável e a ações de promoção à saúde, Quer individuais ou coletivas, na prática diária dos serviços, a percepção da população usuária parece não se configurar dessa forma ${ }^{(18)}$.

Existe um conjunto de ações Que poderiam minimizar situações agressivas no contexto de atenção em saúde, como: melhorar a organização do serviço, facilitar o acesso e o atendimento do usuário, oferecer-lhe informações e encaminhamentos de forma correta e a maior integração e bom relacionamento da equipe ${ }^{(17)}$.

Outro fator ressaltado pelos depoentes foi a discriminação dos usuários em relação ao hospital público e o fato de a maior parte da população atendida ser de baixa renda, conforme se pode confirmar nos seguintes relatos:

Acho Que Quando chegam aqui já vêm discriminando o hospital público, eles já vem armados porQue não tiveram condições financeiras de ir pra outro lugar, então eles já chegam achando Que a gente é um bicho, Que vai tratar mal, então por mais que a gente faça, não consegue agradar, sempre acham que é pouco. (TE6)

[...] eu acho que é porque é hospital público, eles acham que podem fazer do jeito Que Querem, Que não tem regra, tudo é do jeito Que eles Querem, Que eles podem fazer tudo, acho mais Que foi por isso. (EI)

É pela população bem pobre, bem carente, carente de atenção é... de tudo. (...) eu acho que fica assim... pela carência mesmo da própria cultura deles. (E2)

Há uma discriminação em relação ao serviço público de saúde por parte dos usuários Que têm a concepção de Que o atendimento oferecido é de má Qualidade e Que as instituições públicas não possuem regras em seu funcionamento.

A demanda de usuários dos hospitais públicos do Estado é Quase totalmente composta pela população carente. Isso pressupõe uma Questão cultural e educacional, Que pode levar a incompreensão das regras estabelecidas na instituição e menor tendência a obedecêlas, assim como para tentar instituir um bom relacionamento com os trabalhadores, Que determinam tais regras. Assim, observa-se Que o conceito de Qualidade é manifesto individualmente pelas pessoas. Portanto, essa filosofia deve ser adaptada à realidade de cada instituição, visto Que cada serviço de saúde deve buscar alcançar a Qualidade com base em seus indicadores, suas possibilidades, seus valores, suas características e seus usuários, considerando aspectos como a diversidade na cultura, clima e 
condições socioeconômicas presentes na sua região(19).

Diante de um mesmo serviço, as pessoas apresentam diferentes opiniões sobre a Qualidade do cuidado prestado, havendo, assim, uma dificuldade em se estabelecer um consenso sobre a Qualidade, visto Que a percepção sobre esse atributo sofre influência até mesmo do "estado de espírito" do usuário no momento da avaliação ${ }^{(20)}$.

Durante as entrevistas, em nenhum momento, os profissionais atribuíram para si alguma parcela de culpa pelas atitudes violentas advindas do próprio usuário ou acompanhante. Esse fato é Questionável por ser de conhecimento de todos Que os profissionais de enfermagem possuem uma sobrecarga de trabalho devido às inúmeras tarefas a cumprir, associadas à Quantidade insuficiente de pessoal e à jornadas duplas de trabalho.

Observa-se Que embora o SUS tenha avanços importantes e se verifieue considerável mudança em relação ao acesso às ações e aos serviços, muito ainda precisa ser feito. Nesse sentido, os profissionais de saúde necessitam responsabilizar-se cada vez mais para o estabelecimento da saúde como direito do cidadão, devendo o Estado comprometer-se em promover condições para Que tanto os profissionais Quanto as instituições sejam capazes de oferecer uma assistência de Qualidade à populaçãa ${ }^{(18)}$.

A violência em suas várias formas e complexidade sempre ocasiona e perpetua "violências menores", como por exemplo: negligências, imperícias, assistência inadequada, baixa auto-estima, entre outras. Essas fortificam e desencadeiam as violências estruturais (imposição de sobrecarga física e mental aos trabaIhadores) em um ciclo vicioso, o Que mostra a necessidade do entendimento desse processo para seu rompimento com a finalidade de uma auto-realização profissional e humana dos trabalhadores de enfermagem ${ }^{(12)}$.

Por essas diferentes razões e circunstâncias, a assistência prestada ao usuário nem sempre acontece de forma eficaz, pois, em alguns momentos, não há, por parte do profissional, tolerância e atenção requeridas, limitando-se a um cuidado técnico, negligente, sem vínculo durante todo o processo do cuidar. Em consequência disso ocorre um descontentamento Que pode resultar em represálias tanto por parte da equipe como por parte dos usuários do serviço.

\section{CONSIDERAÇÕES FINAIS}

Os resultados obtidos mostraram Que os profissionais de enfermagem estão expostos constantemente a riscos de violência institucional, em geral, por ser a categoria Que passa mais tempo e em maior interação com o paciente e seu acompanhante.

Ao buscar conhecer as vivências de violência sofridas pela equipe de enfermagem no seu ambiente de trabalho, pôde-se constatar Que esses profissionais encontram-se expostos a atitudes violentas predominantemente de natureza verbal. Porém, agressões físicas também foram vivenciadas. A maioria dos sujeitos participantes do estudo demonstrou Que a ocorrência dessas atitudes influenciou no seu cotidiano de trabalho de forma positiva ou negativa. Como benefícios relataram Que a partir dessas vivências buscaram uma melhora na Qualidade da assistência prestada ao usuário. Já como consequências negativas, evidenciaram o estresse, a baixa autoestima e o desestímulo na realização de suas atividades. Outros participantes afirmaram ainda Que a violência não influencia na rotina de trabalho tornando evidente a banalização da violência.

Também foi constatado Que os atos violentos influenciam de forma positiva na organização do serviço de saúde, pois contribuem para Que ocorram mudanças importantes na instituição com consequentes melhorias na Qualidade do serviço prestado.

A ocorrência de atitudes violentas é atribuída pelos profissionais a diversos fatores tais como: a preocupação e angústia dos acompanhantes diante de seu familiar enfermo, o estresse do cotidiano aliado à dificuldade de acesso ao serviço de saúde, a discriminação com a instituição por ser de atendimento público e o fato da população atendida ser carente.

Atualmente há uma necessidade de incluir a violência no pensamento e na ação da saúde. O estudo demonstra Que a violência no local de trabalho em saúde e, especificamente em enfermagem, vem se tornando um problema de saúde pública prejudicial tanto para a saúde e carreira dos trabalhadores de enfermagem como para a assistência prestada aos usuários.

Assim, verifica-se a importância da implantação de medidas para a prevenção de atos violentos como: melhorar as condições de trabalho com número adeQuado de recursos humanos; capacitar os trabalhadores para o enfrentamento de situações críticas e prevenção de atitudes violentas de pacientes e acompanhantes; destacar a importância de uma gestão de enfermagem inovadora Que busque a Qualidade da assistência prestada ao usuário e possibilite um trabalho mais alegre para a equipe de enfermagem, assim como vise a alcançar os objetivos organizacionais; aperfeiçoar o ambiente de trabalho, estilos de gestão e organização do atendimento a fim de melhorar o acesso e acolhimento das pessoas Que procuram os serviços de saúde; adotar uma relação dialógica com trabalhadores e usuários, com implantação de equipes multiprofissionais para prevenção de ocorrências, orientação e apoio às pessoas afetadas por esse fenômeno; criar protocolo de registro das formas de violência institucional, entre outras, de acordo com a necessidade da instituição.

\section{REFERÊNCIAS}

1. Anchieta VCC, Galinkin AL. Policiais civis: representando a violência. Psicol Soc 2005; 17(I): 29-37.

2. Dahlberg LL, Krug EG. Violência: um problema global de saúde pública. Ciência Saúde Coletiva 2006; I I (supl): I l63-78.

3. Brasil. Portaria no 737, de 16 de maio de 2001. Aprova a Política Nacional de Redução de Morbimortalidade por Acidentes e Violência. Diário Oficial da República Federativa do Brasil 2001 maio; 96(I): 3-8.

4. Minayo MCS. Conceitos, teorias e tipologias de violência: a violência faz mal à saúde individual e coletiva. In: Sousa ER,

organizadores. Curso impactos da violência na saúde. Rio de Janeiro: EAD/ENSP; 2007. p. 24-35.

5. Costa ALRC. As múltiplas formas de violência no trabalho de enfermagem: o cotidiano de trabalho no setor de emergência e urgência clínica de um hospital público [tese]. Ribeirão Preto: Escola de Enfermagem de Ribeirão Preto, Universidade de São Paulo; 2005.

6. Lancman $\mathrm{S}$. O trabalho na rua e a exposição à violência no trabalho: um estudo com agentes de trânsito. Interface Comunicação Saúde Educ 2007; II (21): 79-92. 
7. Krug EG, Dahlberg LL, Mercy JA, Zwi AB, Lozano R. Informe mundial sobre la violencia y la salud. Washington: Organización Panamericana de la Salud; 2003.

8. Lemos MB. A lógica da produtividade capitalista e suas manifestações na formação do enfermeiro [tese]. Curitiba: Universidade Federal do Paraná; 2004.

9. Minayo MCS. O desafio do conhecimento: pesQuisa Qualitativa em saúde. $8^{\text {a }}$ ed. São Paulo: Hucitec; 2004.

10. Contrera-Moreno L, Contrera-Moreno MI. Violência no trabalho em enfermagem: um novo risco ocupacional. Rev Bras Enferm 2004; 57(6): 746-9.

1 I. Alvim NAT, SQuassante ND. Relação equipe de enfermagem e acompanhantes de clientes hospitalizados: implicações para o cuidado. Rev Bras Enferm 2009; 62(1): I I-7.

12. Cezar ES, Marziale MHP. Problemas de violência ocupacional em um serviço de urgência hospitalar da Cidade de Londrina, Paraná, Brasil. Cad Saúde Pública 2006; 22(1): 21 17-2 1.

13. Lacaz FAC, Sato L. Humanização e Qualidade do processo de trabalho em saúde. In: Deslandes, SF. Humanização dos cuidados em saúde: conceitos, dilemas e práticas. Rio de Janeiro: Fiocruz; 2006. p.109-39.

14. Barbosa IA, Silva MJP. Cuidado humanizado de enfermagem: o agir com respeito em um hospital universitário. Rev Bras Enferm 2007; 60(5): 546-51

15. Merhy EE. Sobre o Acolhimento na Rede de Serviços. [citado em: 2004 Mar 12]. Disponível em: http://www.uff.br/ saudecoletiva/professores/merhy/

16. Arone EM, Cunha ICKO. Tecnologia e humanização: desafios gerenciados pelo enfermeiro em prol da integralidade da assistência. Rev Bras Enferm 2007; 60(6): 72 I-3.

17. Kaiser DE, Bianchi F. A violência e os profissionais da saúde na atenção primária. Rev Gaúcha Enferm 2008; 29(3): 362-6.

18. Pontes APM, Cesso RGD, Oliveira DC, Gomes AMT. O princípio de universalidade do acesso aos serviços de saúde: o Que pensam os usuários? Esc Anna Nery Rev Enferm 2009; 13(3): 500-7.

19. Rocha ESB, Trevizan MA. Gerenciamento da Qualidade em um serviço de enfermagem hospitalar. Rev Latino-am Enfermagem 2009; 17(2): 240-5.

20. Vasconcellos PP. Desenvolvimento de um modelo de avaliação da Qualidade do serviço odontológico. [dissertação]. Florianópolis: Centro Tecnológico, Universidade Federal de Santa Catarina; 2002. 